\title{
Nasopharyngeal synovial sarcoma - An oncological surprise
}

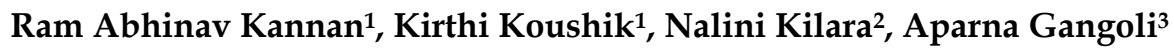 \\ ${ }^{I}$ Department of Radiation Oncology, M S Ramaiah Medical College, Bangalore, India \\ ${ }^{2}$ Department of Medical Oncology, M S Ramaiah Medical College, Bangalore, India \\ ${ }^{3}$ Department of Pathology, HCG Oncology, Bangalore, India
}

Received August 05, 2014; Revised October 04, 2014; Accepted October 05, 2014; Published Online October 09, 2014

\section{Case Report}

\begin{abstract}
Synovial sarcoma is a rare and aggressive high-grade neoplasm with poor prognosis. It is usually encountered in the lower extremities of young adults; only a few cases have been reported in the head and neck region. We report the fourth case of synovial sarcoma of the nasopharynx, treated with neoadjuvant chemotherapy, complete surgical excision and adjuvant radiation with extensive review of literature.
\end{abstract}

Keywords: Synovial Sarcoma; Nasopharynx; Surgery; Radiation; Neoadjuvant Chemotherapy

\section{Introduction}

Synovial sarcoma is a rare malignant tumor that derives from a mesenchymal precursor stem cell that is unrelated to mature synovial tissue. It is an aggressive high-grade neoplasm with poor prognosis. It accounts for about $10 \%$ of all soft tissue sarcomas and the most common location is the lower extremities. Around $10 \%$ of them occur in the head and neck. ${ }^{1,2}$ The nasopharynx is an unusual site for this tumor. Owing to the paucity of cases of synovial sarcoma in the nasopharynx, information regarding appropriate therapy for this tumor is limited. We report the fourth case of a synovial sarcoma arising from the nasopharynx along with a review of the available literature.

\section{Case presentation}

A 19-year-old male presented with complaints of nasal obstruction and intermittent headache that gradually progressed over 1 month. Flexible endoscopic examination revealed a soft tissue mass in the left side of nasopharynx with extension to oropharynx. Computed tomography scan (CT scan) with intravenous contrast revealed an ill-defined mass in the left side of nasopharynx measuring $2.5 \times 3 \times 3.5 \mathrm{cms}$ (Figure 1).

Biopsy of the tissue mass showed malignant spindle cell tumour. Immunohistochemistry revealed tumor cells positive for vimentin, EMA, Bcl-2 with focal expression of CK and negative for SMA and S-100 consistent with the diagnosis of monophasic synovial sarcoma.

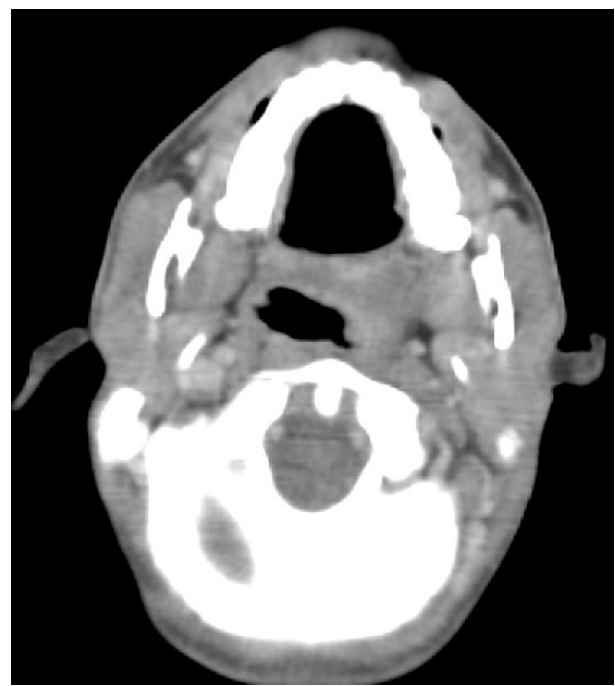

FIG.1: CT scan showing asymmetric soft tissue thickening in the lateral wall of nasopharynx.

[18]-Fluorodeoxyglucose PET-CT scan was done, which showed an asymmetric soft tissue thickening in the lateral wall of nasopharynx with extension to left lateral soft palate extending up to left tonsil measuring $3.3 \times 2.6 \mathrm{cms}$ with no significant metabolic activity. Patient underwent three cycles of neoadjuvant ifosfamide and doxorubicin chemotherapy followed by surgical excision of the tumor via oral cavity under general anesthesia. The resected tumor measured $1.5 \times$ $1.5 \mathrm{~cm}$ with focal close posterior margin $(0.3 \mathrm{~cm})$. The histopathological examination and immunohistochemistry was consistent with pre-treatment diagnosis of monophasic syn- 
ovial sarcoma (Figure 2a, 2b, 2c, 2d). Reverse transcriptase polymerase chain reaction (RT-PCR) for SYT-SSX fusion transcript was negative. Further cytogenetic analysis revealed no visible rearrangement of chromosome bands Xp 11 or $18 \mathrm{q} 11$. Since the surgical margins were $<1 \mathrm{~cm}$, patient received postoperative local radiation to a dose of $60 \mathrm{~Gy}$ in 30 fractions using volumetric arc therapy (VMAT).

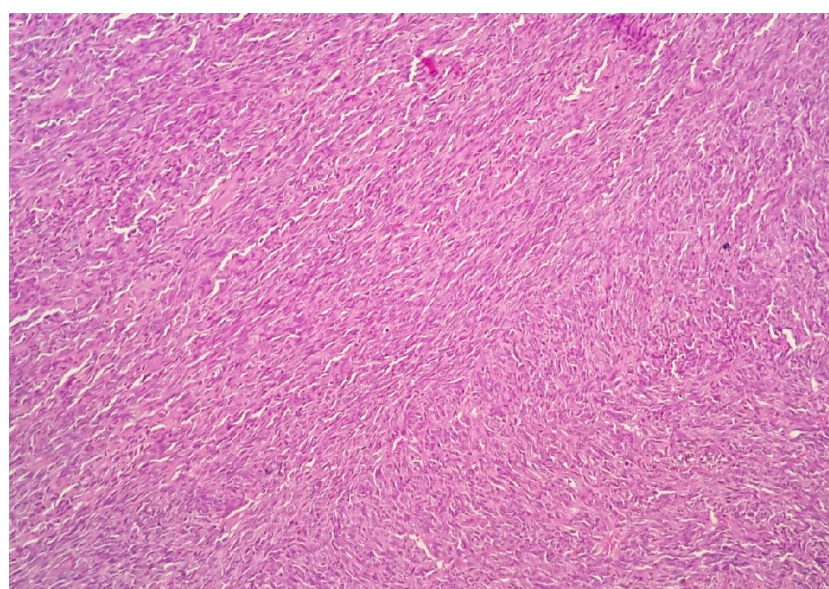

FIG. 2(a): Spindle cells with hyperchromatic nuclei arranged in fascicles and in interlacing pattern.

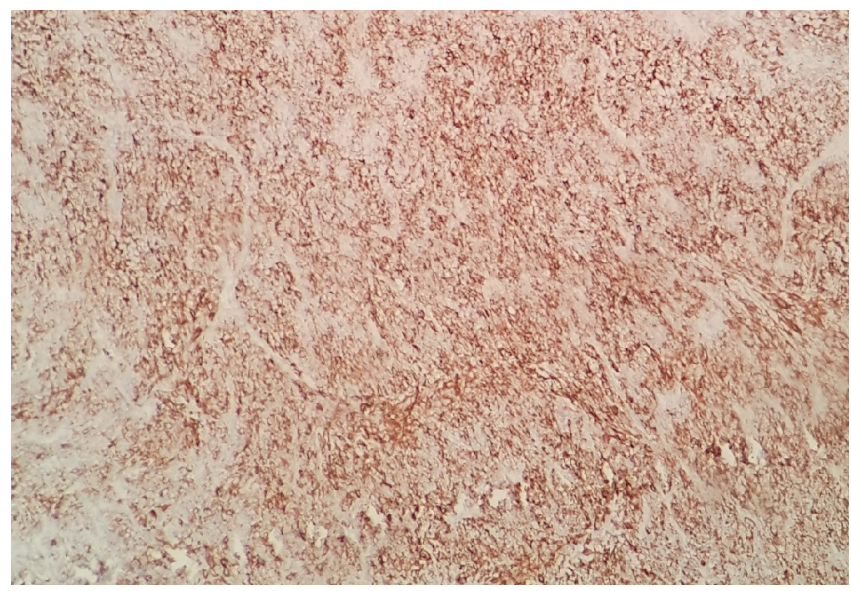

FIG. 2(b): Bcl-2 positivity.

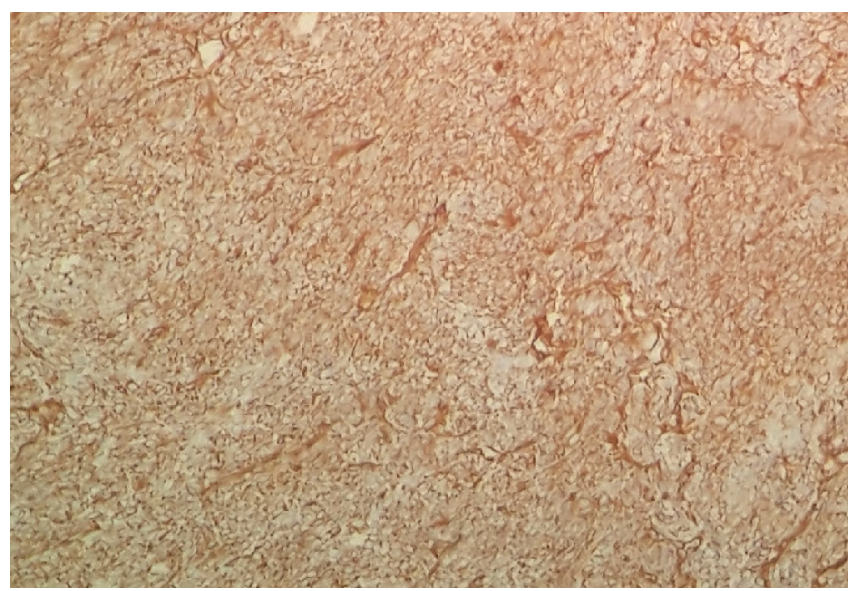

FIG. 2(c): Vimentin Positivity.

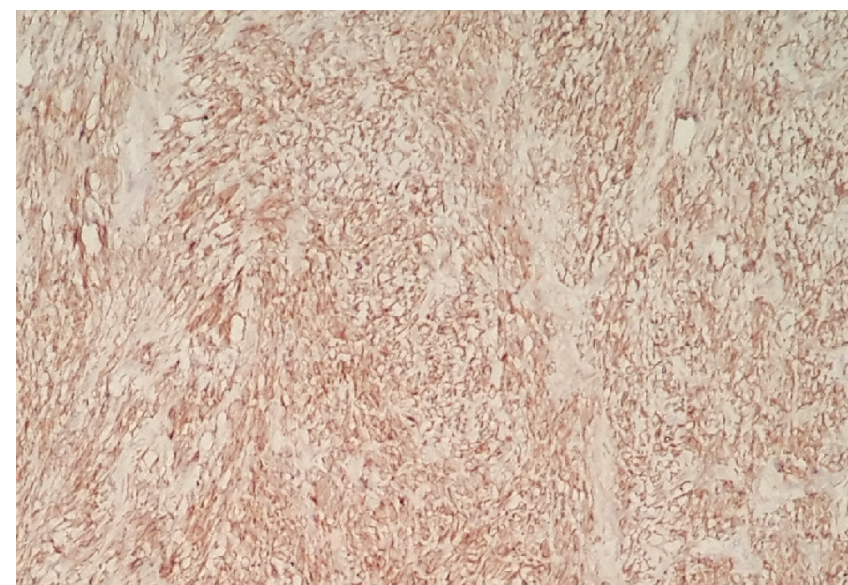

FIG. 2(d): Epithelial Membrane Antigen positivity.

\section{Discussion}

Head and neck synovial sarcoma presents both diagnostic and treatment challenges because of the limitations of knowledge and experience for this neoplasm. Median age of occurrence is in the third decade with a male preponderance of 3:2. ${ }^{3}$ Of these, synovial sarcomas of the nasopharynx are an extremely rare entity. Only three previous cases arising in the nasopharynx have been described in the literature. ${ }^{4,5,6}$

There are two forms of synovial sarcoma; the biphasic and monophasic. The biphasic type is the classic type that contains epithelial and spindle-cell components in various proportions, whereas the monophasic fibrous type contains only spindle cells. The $t(X ; 18)$ translocation is a specific marker of synovial sarcomas. SYT-SSX1, SYT-SSX2, or the rarest SYT-SSX4 gene fusion product is derived from $t(x ; 18)$ (p11.2;q11.2) and currently considered as a tumor-specific genetic hallmark because it is present in more than $95 \%$ of cases. ${ }^{5,7}$ No visible rearrangement of chromosome bands is seen in a small proportion of synovial sarcomas. ${ }^{8}$

The primary treatment of synovial sarcoma is a wide surgical excision to obtain tumor-free margins. However, this cannot always be accomplished in nasopharyngeal cases because of the proximity of the tumor to vital structures. ${ }^{5}$ Tumors tend to spread beyond their visible and palpable limits. ${ }^{9}$ Most authors report that patients treated with surgery and adjuvant radiotherapy had higher survival and lower recurrence rates than did those treated with surgery alone. ${ }^{3}$ Also the overall value of the postoperative RT in soft tissue sarcomas has been found to be maximal in synovial sarcoma of the head and neck. ${ }^{10}$ Lung is the most common site of metastases $(>90 \%) .{ }^{11}$ The value of chemotherapy in enhancing disease-free survival has not been firmly established. Lenoir et al. ${ }^{12}$, reported a dramatic regression in tumor size in a 15-month-old patient with a retropharyngeal synovial sarcoma after initial treatment with a combination of Ifosfamide, Vincristine, and Actinomycin D. Post-operative chemotherapy has also been advocated for prevention/delay 
of distant metastases although its role remains to be established

Favorable prognostic indicators include an early diagnosis, small tumor size $(<5 \mathrm{~cm})$, younger age $(<20 \mathrm{yr})$, and a wide surgical excision. ${ }^{13,14,15}$ Of these, tumor size is the single most important prognostic determinant, as tumors of $>10 \mathrm{~cm}$ in diameter are associated with a poor prognosis. ${ }^{16}$ DNA ploidy may also be an important prognostic factor, with aneuploid tumors reported to diminish survival. ${ }^{17}$ Extensive osteoid and bone formation in synovial sarcomas was found to be associated with a favorable prognosis. ${ }^{18}$

\section{Conflict of interest}

The authors declare that they have no conflicts of interest. The authors alone are responsible for the content and writing of the paper.

\section{References}

1. Trassard M, Le Doussal V, Hacène K, et al. Prognostic factors in localized primary synovial sarcoma: a multicenter study of 128 adult patients. $J$ Clin Oncol 2001; 19:525-34.

2. Ferrari A, Gronchi A, Casanova M, et al. Synovial sarcoma: a retrospective analysis of 271 patients of all ages treated at a single institution. Cancer 2004; 101:627-34.

3. Harb WJ, Luna MA, Patel SR, et al. Survival in patients with synovial sarcoma of the head and neck: association with tumor location, size, and extension. Head Neck 2007; 29:731-40.

4. Verma A, Mehta S, Mann SBS, Radotra BD. Synovial sarcoma of the nasopharynx. Ear Nose Throat $J$ 2002; 81:36-9.

5. Lin HC, Friedman M, Kuo FY, Huang HY. Synovial sarcoma of the Eustachian tube. Head Neck 2009; 31:1245-8.

6. Nakahira M, Sugasawa M, Morita K. Monophasic synovial sarcoma of the nasopharynx. Auris Nasus Larynx 2013; 40: 413-6.

7. Wenig BM. Atlas of head and neck pathology. Philadelphia, PA: Saunders-Elsevier 2008; 514-21.

8. Limon J, Mrozek K, Mandant N, et al. Cytogenetics of synovial sarcoma: presentation of ten new cases and review of the literature. Genes Chromosomes Cancer 1991; 3: 338-45.

9. Roth JA, Enzinger FM, Tannenbaum M. Synovial sarcoma of the neck: a follow-up study of 24 cases. Cancer 1975; 35:1243-53.

10. Bukachevsky RP, Pincus RL, Shechtman FG, et al. Synovial sarcoma of the head and neck. Head Neck 1992; 14:44-8.
11. Nadig SK, Love MHS, Brooker DS, Hall SJ. Synovial sarcoma in the retropharyngeal space. J Laryngol Otol 2002; 116:224-6.

12. Lenoir P, Ramet J, Goossens A, et al. Retropharyngeal synovial sarcoma in an infant: Report of a case and of its response to chemotherapy; review of the literature. Pediatr Hernatol Oncol 1991:8:45-52.

13. Amble FR, Olsen KD, Nascimento AG, Foote RL. Head and neck synovial cell sarcoma. Otolaryngol Head Neck Surg 1992; 107:631-7.

14. Giaoui L, Salvan D, Casiraghi O, et al. Primary synovial sarcoma of the head and neck. Materials of The Gustave Roussy Institute. Report of 13 cases. Ann Otolaryngol Chir Cervicofac 1999; 116:71-7.

15. Thompson RC Jr, Garg A, Goswitz J, et al. Synovial sarcoma. Large size predicts poor outcome. Clin Orthop Relat Res 2000; 373:18-24.

16. Yokoyama K, Shinohara N, Kondo M, Mashima T. Prognostic factors in synovial sarcoma: A clinicopathologic study of 18 cases. Jpn J Clin Oncol 1995; 25:131-4.

17. El-Nagger AK, Ayala AG, Abdulkarim FW, et al. Synovial sarcoma. A DNA flow cytometric study. Cancer 1990; 65:2295-300.

18. Milchgrub S, Ghandur-Mnaymneh I, Dorfman HD, Albores- Saarendra J. Synovial sarcoma with extensive osteoid and bone formation. Am J Surg Pathol 1993; 17:357-63. 